\title{
The Pregnant and Lactating Mother's KAP (Knowledge, Attitude and Practice) and Nutritional Care during Antenatal and Postnatal Period in Ukhia, Cox's Bazar, Bangladesh
}

\author{
M. N. Hasan ${ }^{1}$, M. N. I. Khan ${ }^{1, *}$ M. Z. Sultan ${ }^{2}$ \\ ${ }^{1}$ Institute of Nutrition and Food Science, University of Dhaka, Dhaka-1000, Bangladesh \\ ${ }^{2}$ Centre for Advanced Research in Sciences, University of Dhaka, Dhaka-1000, Bangladesh
}

Received 30 June 2015, accepted in final revised form 15 September 2015

\begin{abstract}
The nutritional status of women before, during and after pregnancy contributes a good deal to their own health and, to the health of their children and other family members. In Bangladesh, there is enormous amount of mother and child death and morbidity related to inadequate nutrition, socioeconomic condition, education level, hygienic condition and various care practices. The study was conducted to see the nutritional KAP (knowledge, attitude and practice) during antenatal and postnatal care of the pregnant and lactating mother in Ukhia Upazilla of Cox's Bazar in Bangladesh among 337 pregnant and lactating mothers who had at least one child aged less than five years old by random sampling in 2010 . The antenatal and postnatal care services availability was observed unsatisfactory. The study revealed that the nutritional lacking was not only poverty stricken, but also their poor knowledge, attitude and practice on health, hygiene, reproductive health, antenatal care, post natal care and nutritious food.
\end{abstract}

Keywords: Maternal health; Pregnancy; Lactation; Antenatal Care; Postnatal Care; KAP.

(C) 2016 JSR Publications. ISSN: 2070-0237 (Print); 2070-0245 (Online). All rights reserved. doi: http://dx.doi.org/10.3329/jsr.v8i1.23951 J. Sci. Res. 8 (1), 55-70 (2016)

\section{Introduction}

Maternal and child care practices affects women's health and nutrition during pregnancy, child birth, and lactation and the care provided an infant during breastfeeding, weaning and management of childhood diseases [1]. Pregnancy is an anabolic condition that affects the metabolism of all nutrients in order to support maternal homeostasis, fetal growth and development and to prepare for lactation.

* Corresponding author: nik_infs@yahoo.com 
During pregnancy a women's nutritional needs become greater than at other times in her life [2]. Her diet needs to provide all the elements needed for the growth of a fertilized ovum into a viable fetus and baby [3]. The nutritional stores of a lactating woman may already more or less deplete as a result of pregnancy and the loss of blood during childbirth. Lactation raises nutrient needs, mainly because of the loss of nutrients first through colostrum and through breast milk. Traditional beliefs against colostrum feeding deny new born infants essential nutrients and protection against disease $[4,5]$. Provided that the mother has adequate breast milk, breast feeding alone with no added supplementation is all that is needed for the normal infant during the first six months of life (exclusive breast feeding) where a lactating mother has to continue breast feeding up to two years [6]. This period is very critical for both mother and child. Furthermore, food taboos during pregnancy and lactation can cause serious damage to the health, where any imbalance in this cycle is the cause of malnutrition, morbidity and mortality of both mother and child $[7,8]$.

Addressing maternal health means that all women receive the care for being safe and healthy throughout pregnancy and childbirth. Safe motherhood encompasses social and cultural factors, as well as address health systems and health policy [9]. Indicators used to measure maternal health include skilled attendance at birth, contraceptive prevalence rates and maternal mortality and morbidity [10]. More than half a million women die each year in the world from causes related to pregnancy and childbirth [11]. Motherhood will be safer for women, if they choose to become pregnant and get adequate antenatal care for prevention of pregnancy related complications [12]. Safe motherhood initiates before conception with proper nutrition and a healthy life style and continues with appropriate prenatal care, the prevention of complications when possible, and the early and effective treatment of problems [1315]. Improving maternal health is one of the eight Millennium Development Goals (MDG), and great efforts have been put forth to achieve that goal. Most maternal deaths in developing countries are preventable through adequate nutrition, proper health care, including access to family planning, the presence of a skilled birth attendant during delivery and emergency obstetric care [16]. Bangladesh being one of the developing countries contributes to more than 155.8 million of the world population out of which about $50 \%$ of them are women in the year of 2013-14. Better the status of women in society better is fertility control and reproductive health. So far, the Government of Bangladesh has been implementing various programs in the sectors of maternal health and Bangladesh is on track in terms of reduction of infant and maternal mortality where it achieved total fertility rate per women (15-49) as 2.11, contraceptive prevalence rate (\%) as 58.4. and infant mortality rate (per thousand live birth) as 35 in population census, 2011 [17]. However, much work has yet to be done to assure maternal health for women countrywide. For women in developing countries, however, the reality of motherhood is often grim. For these women, Motherhood is often marred by unforeseen complications of pregnancy and childbirth. Some die in the prime period of their lives and in great distress: from hemorrhage, convulsions, 
obstructed labor or sever infection after delivery or unsafe abortion. The pregnant and lactating mothers of the southern hilly region of the Bangladesh remain vulnerable to different types of health related problem due to insufficient knowledge, attitude and practice (KAP). So, our objective of this study is to assess the pregnant and lactating mother's KAP on nutrition, antenatal and postnatal care practice in Ukhia, Cox's Bazar, Bangladesh which includes socio economic profile, cleanliness of household and personal hygienic practice, dietary intake pattern and cooking method, antenatal care process, check postnatal care management, identify health facilities during pregnancy and lactation, breast feeding practice to newly born baby, the nutrition status of the mother and the newly born baby and make potential recommendations on the basis of study findings.

\section{Experimental}

\subsection{Study design}

The study was conducted among 337 pregnant and lactating mothers who have at least one child aged less than five years by random sampling. The investigated area was the nutritional profile, lifestyle, socio-economic condition, health facilities available in their area, antenatal care, postnatal care, colostrum feeding of the neonate and food intake. The sampling units were chosen at random from various places of Ukhia Upazilla under the District of Cox's Bazar, Bangladesh. A total number of 337 mothers were interviewed who had at least one child less than five years old. Information on socio-economic variables, health profile, caring pattern, dietary intake pattern (food frequency and 24 hour recall method), and anthropometry (height, weight, age) of the mothers were recorded on a pretested questionnaire. It was also assessed on breast feeding practices during postnatal care; hygiene and sanitation practices and, morbidity and treatment practices.

\subsection{Study location and time frame}

The survey was conducted from 10-14 ${ }^{\text {th }}$ March, 2010 at Ukhia Upazilla of Cox's Bazar, Bangladesh.

\subsection{Statistical analysis}

After rechecking all data, they were analyzed using PC, SPSS software package. Descriptive studies (frequencies, descriptive, cross tabs) and compare means were used to calculate all variables. Values were expressed as percentage, mean and standard deviation (SD). 


\section{Results and Discussions}

The findings of the study are presented in seven sections [18]. The first section deals with the socio-economic profile of the studied population (Tables 1-3). The second section provides information about mother's environmental sanitation and hygiene (Table 4). The third section gives a vivid picture about their cooking method and hygiene during cooking (Table 5). The fourth section provides various information about pregnant mother delivery place and assistance, personal hygiene, family planning status, pregnancy complications, vaccination profiling, and delivery type's etc. (Tables 6-8). The fifth section provides data about food intake during pregnancy (Tables 9,10). The sixth section provides information about mother's BMI (body mass index) (Table 11) and the seventh section gives the information about mother's knowledge on balance diet, various diet related diseases and postnatal care practice behavior (Tables 12-14).

Table 1. Age distribution of the targeted mothers and fathers.

\begin{tabular}{llll}
\hline Parameters & Frequency & Percentage & Mean \pm SD \\
\hline Age of father & & & \\
$\leq 29$ & 49 & 14.5 & $24.91 \pm 2.73$ \\
$29.01-38$ & 98 & 29 & $33.50 \pm 2.82$ \\
$38.01-47$ & 94 & 28.1 & $43.11 \pm 2.71$ \\
$47.01-55$ & 52 & 15.4 & $51.44 \pm 2.45$ \\
$\geq 55.01$ & 44 & 13 & $65.17 \pm 8.30$ \\
Total & 337 & 100 & $41.85 \pm 12.74$ \\
Age of mother & & & \\
$\leq 25$ & 95 & 28.30 & $22.31 \pm 2.93$ \\
$25.01-35$ & 134 & 39.62 & $30.46 \pm 3.02$ \\
$35.01-45$ & 82 & 24.53 & $40.60 \pm 3.08$ \\
$45.01-55$ & 18 & 5.35 & $50.71 \pm 3.04$ \\
$\geq 55.01$ & 8 & 2.20 & $67.14 \pm 10.49$ \\
Total & 337 & 100 & $32.54 \pm 10.12$ \\
\hline
\end{tabular}

Marriage in most Asian societies defines the onset of the socially acceptable time for childbearing. Women who marry early will have, on average, a longer period of exposure to pregnancy, often leading to a higher number of children ever born. The onset of childbearing at early age has a direct effect on mother's health. Now a day's women employment and education is the main cause for rising the mean age of marriage (Table 1). Our study showed that around 28\% mother's age is less than or equal to 25 years. Mean age of marriage was less than 18 years (Table 1).

Table 2. Distribution of the targeted mothers by their socio-economic profile.

\begin{tabular}{lll}
\hline Parameters & Frequency & Percentage \\
\hline Father's education & & \\
$\leq$ Class 5 & 72 & 31 \\
Class (6-8) & 39 & 12 \\
Class (9-10) & 25 & 7 \\
Class $\geq 11$ & 201 & 60 \\
\hline
\end{tabular}




\begin{tabular}{lll}
\hline Parameters & Frequency & Percentage \\
\hline Total & 337 & 100 \\
Father's occupation & & \\
Farmer & 36 & 10.8 \\
Rickshaw puller & 30 & 9 \\
Driver & 26 & 7.7 \\
Business & 95 & 28.1 \\
Unemployed & 15 & 4.3 \\
Others & 135 & 40.1 \\
Total & 337 & 100 \\
Mother education level & & \\
$\leq$ Class 5 & 59 & 3.9 \\
Class (6-8) & 28 & 3.1 \\
Class (9-10) & 33 & 4.7 \\
Class $\geq 11$ & 217 & 88.3 \\
Total & 337 & 100 \\
Mothers occupation & & \\
Housewife & 299 & 89.03 \\
Others & 38 & 10.97 \\
Total & 337 & 100 \\
Monthly capita household income & \\
$\leq 2500$ & 16 & 4.70 \\
2501-5000 & 107 & 31.8 \\
5001-7500 & 85 & 25.2 \\
7501-10000 & 56 & 16.6 \\
$>10000$ & 73 & 21.7 \\
Total & 337 & 100 \\
\hline
\end{tabular}

Maternal education level was classified into four groups- finished their primary level, secondary level, higher secondary level and highly educated. Around 88\% mother read more than class 11 .

Among the mothers, $89 \%$ were housewives. On the other hand, farmers, businessmen, rickshaw puller and drivers were the major occupation of the fathers (Table 2).

When the women were grouped on the basis of their per capita income, most of them come from the families where the per capita income was between Taka 25015000 (Table 2).

Table 3. Distribution of per capita expenditure for basic human needs.

\begin{tabular}{lll}
\hline Expenditure sectors & Per capita expenditure in Taka & $\begin{array}{l}\text { Percentage of total } \\
\text { expenditure }\end{array}$ \\
\hline Food & 964.30 & 64.45 \\
Education & 133.94 & 8.95 \\
Medicine & 107.38 & 7.18 \\
Transport & 76.00 & 5.08 \\
Housing & 15.15 & 1.01 \\
Clothes & 129.19 & 8.64 \\
Others & 70.18 & 4.69 \\
\hline
\end{tabular}


Study reveals that most of the family income was expensed in food and education. Other major contributors of expenses were medicine and clothing. Most of the family owns their own house, so expense in housing was low (Table 3).

Table 4. Distribution of mothers by their environmental hygiene and sanitation.

\begin{tabular}{|c|c|c|}
\hline Parameters & Frequency & Percentage \\
\hline \multicolumn{3}{|l|}{ Types of houses } \\
\hline Concrete & 16 & 4.7 \\
\hline Tin shaded & 48 & 14.2 \\
\hline All tin+floor concrete & 6 & 1.8 \\
\hline All tin+Muddy floor & 3 & 0.9 \\
\hline All tin+soil wall & 102 & 30.3 \\
\hline Straw roof + soil wall & 134 & 39.8 \\
\hline $\begin{array}{l}\text { Straw roof }+ \text { bamboo/straw } \\
\text { wall }\end{array}$ & 18 & 5.3 \\
\hline Others & 10 & 3 \\
\hline Total & 337 & 100 \\
\hline \multicolumn{3}{|l|}{ Kitchen status } \\
\hline Yes & 251 & 74.5 \\
\hline No & 86 & 25.5 \\
\hline Total & 337 & 100 \\
\hline \multicolumn{3}{|l|}{ Source of drinking water } \\
\hline Tube-well & 335 & 99.4 \\
\hline Well & 2 & 0.6 \\
\hline Total & 337 & 100 \\
\hline \multicolumn{3}{|l|}{ Source of cooking water } \\
\hline Tube-well & 334 & 99.11 \\
\hline Well & 2 & 0.6 \\
\hline Pond & 1 & 0.3 \\
\hline \multicolumn{3}{|l|}{ River } \\
\hline \multicolumn{3}{|l|}{ Boiling of river's water } \\
\hline Total & 337 & 100 \\
\hline \multicolumn{3}{|l|}{ Place of garbage disposal } \\
\hline Separate pit/place & 162 & 48.1 \\
\hline Surrounding of the house & 166 & 49.3 \\
\hline Here and there & 4 & 1.2 \\
\hline Total & 337 & 100 \\
\hline \multicolumn{3}{|l|}{ Types of toilet used } \\
\hline Don't have latrine & 25 & 7.4 \\
\hline Open latrine & 35 & 10.4 \\
\hline Separate pit & 105 & 31.2 \\
\hline Sanitary latrine & 170 & 50.4 \\
\hline Others & 2 & 0.6 \\
\hline Total & 337 & 100 \\
\hline \multicolumn{3}{|c|}{ Use of slippers during latrine use } \\
\hline Yes & 168 & 49.9 \\
\hline No & 169 & 50.1 \\
\hline Total & 337 & 100 \\
\hline \multicolumn{3}{|l|}{ Washing hand before eating } \\
\hline All times & 287 & 85.2 \\
\hline Sometimes & 36 & 10.7 \\
\hline No & 14 & 4.2 \\
\hline Total & 337 & 100 \\
\hline
\end{tabular}


Housing characteristics of survey respondents showed that in Ukhia (Bangladesh) $41 \%$ households had access to electricity, whereas in urban areas situation was much better. Among the study population, $74.5 \%$ had their own kitchen (Table 4).

Information on household sources of drinking water is important because of fatal diseases, including typhoid, cholera and dysentery, are predominant in unprotected water sources. Our study showed that about $99.11 \%$ households drink tube-well water (Table 4).

Access to adequate sanitation facilities is an important determinant of health conditions. Our study showed that $50.4 \%$ households use sanitary latrine (Table 4 ).

Forty-eight percent of the households disposed of their garbage at specific place outside house, whereas $49.3 \%$ disposed of their garbage in the surrounding of the house. About $50 \%$ of the household members did not use slippers during passing dirt or toilet. Eighty five percent of households washed their hand before eating (Table 4).

Table 5. Distribution of mother's according to their cooking method and their hygiene during cooking.

\begin{tabular}{lll}
\hline Parameters & Frequency & Percentage \\
\hline Place of eating food & & \\
Kitchen & 181 & 54.3 \\
In the yard on the mat & 81 & 24 \\
Bed/table/chair & 61 & 18.1 \\
Others & 13 & 3.9 \\
Total & 337 & 100 \\
Covering of food after cooking & \\
Yes & 327 & 97 \\
No & 5 & 1.5 \\
Sometimes & 5 & 1.5 \\
Total & 337 & 100 \\
Eating unveil and waste food & & \\
Yes & 187 & 55.5 \\
No & 150 & 44.5 \\
Total & 337 & 100 \\
Cleaning of hand, cooking utensils before cooking & \\
Yes & 335 & 99.4 \\
No & 2 & 0.6 \\
Total & 337 & 100 \\
Use of gruel & & \\
Never give it up & 234 & 69.44 \\
Feed to the children & 8 & 2.4 \\
Feed to the cattle & 17 & 5.0 \\
Discard it & 74 & 22 \\
Others & 4 & 1.2 \\
Total & 337 & 100 \\
Cleaning of vegetables before cooking & \\
Make small part+wash with & 163 & 48.4 \\
water & & \\
Raw wash+then cut & 121 & 35.9 \\
Use both process & 53 & 15.7 \\
Total & 337 & 100 \\
\hline
\end{tabular}




\begin{tabular}{lcl}
\hline Parameters & Frequency & Percentage \\
\hline Discard water after boiling vegetables & \\
Yes & 115 & 34.1 \\
No & 222 & 65.9 \\
Total & 337 & 100 \\
Use of oil during cooking leafy vegetables & \\
Yes & 322 & 95.6 \\
No & 1 & 0.3 \\
Sometimes & 14 & 4.2 \\
Total & 337 & 100 \\
Lidding of vegetables during cooking & \\
Yes & 321 & 95.3 \\
No & 16 & 4.7 \\
Total & 337 & 100 \\
Use of salt & & \\
Packet salt & 140 & 41.5 \\
Open salt & 182 & 54 \\
Both (Packet + Open) & 15 & 4.5 \\
Total & 337 & 100 \\
Storage of salt & & \\
Open & 16 & 4.7 \\
Covered pot & 299 & 88.7 \\
Open pot & 22 & 6.5 \\
Total & 337 & 100 \\
\hline
\end{tabular}

Among the respondent 55.5\% were found to consume unveil food, $48.4 \%$ washed vegetables after chopping it. $95.6 \%$ used oil during cooking leafy vegetables, $41.5 \%$ used iodized salt during cooking, 54\% used open salt and $88.7 \%$ covered their salt during storing. $69.44 \%$ did not discard their rice gruel; only $2.4 \%$ fed it to the children and $5 \%$ to the cattle (Table 5 ).

Table 6. Distribution of targeted mother's by health service facilities in their locality and adoption of family planning.

\begin{tabular}{lll}
\hline Parameters & Frequency & Percentage \\
\hline \multicolumn{2}{l}{ Types of health service providing organization } & \\
Govt. hospital & 94 & 27.9 \\
Private clinic & 5 & 1.5 \\
NGO clinic & 53 & 15.7 \\
Union FWV Centre & 20 & 5.9 \\
TBA/Pregenitrix & 19 & 5.6 \\
MBBS doctor & 73 & 21.7 \\
Paramedics/ Asst. health & 37 & 11 \\
worker & & \\
Others & 36 & 10.7 \\
Total & 337 & 100 \\
Family planning practices & & \\
Yes & 208 & 61.7 \\
No & 129 & 38.3 \\
Total & 337 & 100 \\
\hline
\end{tabular}


Results indicated that the maximum (28\%) available health service providers in locality were the Government hospitals (Table 6).

Sixty two percent women adopted family planning practices; on the other hand, about $38 \%$ did not (Table 6).

Table 7. Distribution of mother's by their adoption of antenatal checks.

\begin{tabular}{lll}
\hline Parameters & Frequency & Percentage \\
\hline Times of antenatal checkup visit & \\
Less than 3 & 109 & 32.3 \\
More than 3 & 106 & 31.5 \\
Never ever & 47 & 13.9 \\
3 times & 5 & 1.5 \\
Can't recognized & 12 & 3.6 \\
Not applicable & 58 & 17.2 \\
Total & 337 & 100 \\
Reason of refusing antenatal checks & \\
Didn't feel necessary & 88 & 26.1 \\
Family obligations & 15 & 4.5 \\
Transport problem & 7 & 2.1 \\
Lack of facilities & 37 & 11 \\
Not applicable & 178 & 52.8 \\
No knowledge & 5 & 1.4 \\
Others & 7 & 2.1 \\
Total & 337 & 100 \\
TT vaccination status & & \\
Yes & 279 & 82.8 \\
No & 58 & 17.2 \\
Total & 337 & 100 \\
Iron tablet intake status & & \\
Yes & 224 & 66.5 \\
No & 113 & 33.5 \\
Total & 337 & 100 \\
Folic acid tablet intake status & \\
Yes & 65 & 19.3 \\
No & 246 & 73 \\
Don't understand & 21 & 6.2 \\
Never hear & 5 & 1.5 \\
Total & 337 & 100 \\
\hline & &
\end{tabular}

Antenatal care coverage increased sharply in these years but our study showed that only $1.5 \%$ mother sought three antenatal checkups, $32.3 \%$ taken less than 3 and about $14 \%$ did not ever go for checkups because of that they did not feel its necessity. Among the studied mother, $82.8 \%$ completed their TT vaccination timely and $17.2 \%$ had not taken vaccine at all (Table 7).

Data showed that $66.5 \%$ mothers had taken iron tablets during pregnancy. On the other hand, only $19.3 \%$ had taken folic acid tablet (Table 7).

The study revealed that about $90 \%$ delivery occurred at home and among them about $96 \%$ infants were live and well. About $62 \%$ mother's delivery attendance was done by Temporary Birth Attendant (TBA), only 3\% mothers faced surgery during 
delivery, $44 \%$ mothers faced no problem during pregnancy and around $45 \%$ women married at the age of 16-18 years(Table 8).

Table 8. Distribution of mothers by delivery mode, place, assistance and cooperation.

\begin{tabular}{|c|c|c|}
\hline Parameters & Frequency & Percentage \\
\hline \multicolumn{3}{|l|}{ Birth condition of the child } \\
\hline Live and well & 323 & 95.8 \\
\hline Died & 5 & 1.5 \\
\hline Ill & 9 & 2.7 \\
\hline Total & 337 & 100 \\
\hline \multicolumn{3}{|l|}{ Place of child delivery } \\
\hline Home & 302 & 89.6 \\
\hline Hospital & 25 & 7.4 \\
\hline Clinic & 6 & 1.8 \\
\hline UPHCC & 4 & 1.2 \\
\hline Total & 337 & 100 \\
\hline \multicolumn{3}{|l|}{ Attendance at delivery } \\
\hline Docter & 38 & 11.3 \\
\hline TBA/ pergenitrix & 208 & 61.7 \\
\hline Relatives/neighbor & 88 & 26.1 \\
\hline No one & 3 & 0.9 \\
\hline Total & 337 & 100 \\
\hline \multicolumn{3}{|l|}{ Types of delivery } \\
\hline Normal & 327 & 97 \\
\hline Surgery & 10 & 3 \\
\hline Total & 337 & 100 \\
\hline \multicolumn{3}{|l|}{ Birth weight of the newborn } \\
\hline$\leq 2.49$ & 12 & 3.6 \\
\hline $2.5-3.5$ & 40 & 11.9 \\
\hline$\geq 3.6$ & 244 & 72.4 \\
\hline Don't know & 41 & 12.7 \\
\hline Total & 337 & 100 \\
\hline \multicolumn{3}{|c|}{ Health complications faced during pregnancy } \\
\hline Edema & 52 & 15.4 \\
\hline Convulsion & 7 & 2.1 \\
\hline High pressure & 1 & 0.3 \\
\hline Urinary Tract Inflammation & 3 & 0.9 \\
\hline Pain in the lower abdomen & 53 & 15.7 \\
\hline Pain in the upper abdomen & 5 & 1.5 \\
\hline Coughing & 3 & 0.9 \\
\hline Bleeding & 1 & 0.3 \\
\hline Vomiting & 52 & 15.4 \\
\hline Others & 9 & 2.7 \\
\hline No problem & 150 & 44.4 \\
\hline Total & 337 & 100 \\
\hline \multicolumn{3}{|c|}{ Cooperation received from husband } \\
\hline Good & 202 & 60 \\
\hline Average & 117 & 34.8 \\
\hline $\mathrm{Bad}$ & 15 & 4 \\
\hline Very bad & 6 & 1.2 \\
\hline Total & 337 & 100 \\
\hline \multicolumn{3}{|c|}{ Cooperation received from the family members } \\
\hline
\end{tabular}




\begin{tabular}{lll}
\hline Parameters & Frequency & Percentage \\
\hline Good & 190 & 61.6 \\
Average & 101 & 30.2 \\
Bad & 17 & 4.9 \\
Very bad & 9 & 2.4 \\
Not applicable & 20 & 6.1 \\
Total & 337 & 100 \\
Mothers age at marriage & & \\
$<16$ & 125 & 37.10 \\
$16-18$ & 150 & 44.51 \\
$>18$ & 62 & 18.39 \\
Total & 337 & 100 \\
\hline
\end{tabular}

Table 9. Distribution of mothers by food intake during pregnancy.

\begin{tabular}{lll}
\hline Parameters & Frequency & Percentage \\
\hline Amount of food consumed & & \\
More than normal & 81 & 24 \\
Less than normal & 163 & 48.4 \\
Same as before & 82 & 24.3 \\
As before but selective & 2 & 0.6 \\
Not applicable & 9 & 2.7 \\
Total & 337 & 100 \\
The food intake pattern in case of excess consumption & \\
Large amount in 1 time & 25 & 7.4 \\
Greater amount in every & 44 & 13.1 \\
times & & \\
Frequently but small & 48 & 14.2 \\
amount & & \\
Others & 16 & 4.7 \\
Not applicable & 204 & 60.5 \\
Total & 337 & 100 \\
Food insufficiency faced & & \\
Yes & 142 & 42.1 \\
No & 195 & 57.9 \\
Total & 337 & 100 \\
\hline
\end{tabular}

Among the study population, $24 \%$ mother's took more than average food during their pregnancy, on the contrary, $48.5 \%$ women consumed less than normal during the period of pregnancy and $24.3 \%$ took same amount of food as before (Table 9).

Among $24 \%$ of the women took food more than average, about $7.4 \%$ took large amount in one time. $13.1 \%$ took greater amount in every time. $14.2 \%$ took frequently but small amount (Table 9).

Table 10. Weekly food consumption pattern (mean days \pm SD).

\begin{tabular}{llll}
\hline Food source & Morning & Noon & Night \\
\hline Plant source & & & \\
Rice & $6.63 \pm 1.14$ & $7.17 \pm 3.44$ & $7.18 \pm 3.44$ \\
Bread & $3.84 \pm 2.05$ & $5.67 \pm 2.31$ & $4.38 \pm 2.86$ \\
Leafy vegetables & $3.98 \pm 1.97$ & $4.16 \pm 1.90$ & $3.98 \pm 1.99$ \\
Non leafy veg. & $4.99 \pm 2.02$ & $5.02 \pm 1.99$ & $5.00 \pm 2.82$ \\
\hline
\end{tabular}




\begin{tabular}{llll}
\hline Food source & Morning & Noon & Night \\
\hline Fruits & $3.26 \pm 2.35$ & $3.09 \pm 1.94$ & $2.73 \pm 1.91$ \\
Dal & $2.79 \pm 1.92$ & $2.39 \pm 2.02$ & $2.68 \pm 1.70$ \\
Animal source & & & \\
Fish & $4.02 \pm 2.17$ & $4.31 \pm 2.35$ & $4.18 \pm 2.02$ \\
Meat & $1.53 \pm 1.07$ & $1.81 \pm 1.24$ & $1.69 \pm 1.04$ \\
Egg & $2.70 \pm .94$ & $2.41 \pm 1.61$ & $2.34 \pm 1.52$ \\
Milk & $3.75 \pm 2.54$ & $4.03 \pm 2.62$ & $3.81 \pm 2.50$ \\
Milk products & $4.50 \pm 3.50$ & $2.57 \pm 2.25$ & $2.20 \pm 1.10$ \\
\hline
\end{tabular}

The dietary pattern of the mother's showed that in classification of food group, mothers were not regular in consuming body protective food like fruits and leafy vegetables, and moderate intake of non-leafy vegetables were found. Therefore, there must be a scope of micronutrient deficiency disease. The study respondents were used to consume very less frequently the body building foods, like animal and vegetable protein. They used to consume fish and meat at a ratio of 1 or 2 times per week. Besides this, egg consumption was not regular. They consumed pulse (dal) on average 2 or 3 times per week. Milk and milk product consumption pattern was not meeting the acceptable daily intake properly (Table 10).

Table 11. Distribution of mother's by BMI.

\begin{tabular}{lll}
\hline Parameters & Frequency & Percentage \\
\hline Mother's BMI & & \\
$<18.5$ & 71 & 21 \\
$18.5-25$ & 200 & 59.6 \\
$25-30$ & 55 & 16.3 \\
$>30$ & 11 & 3.1 \\
Total & 337 & 100 \\
\hline
\end{tabular}

Study showed that among the mothers $59.6 \%$ women's nutritional status were in normal range by BMI classification, where we found $21 \%$ women were malnourished, $16.3 \%$ women were overweight and around $3 \%$ women were obese (Table 11).

Table 12. Distribution of mother's by their knowledge about balance diet and different common disease related to hygiene and nutrition.

\begin{tabular}{lcl}
\hline Parameters & Frequency & Percentage \\
\hline Knowledge about balance diet & \\
Knew & 107 & 31.8 \\
Don't know & 230 & 68.3 \\
Total & 337 & 100 \\
Knowledge about protective food & \\
Knew & 122 & 36.2 \\
Don't know & 215 & 63.8 \\
Total & 337 & 100 \\
Etiology of night blindness & \\
Knew & 129 & 38.2 \\
Don't know & 208 & 61.8 \\
Total & 337 & 100 \\
\hline
\end{tabular}




\begin{tabular}{lll}
\hline Parameters & Frequency & Percentage \\
\hline Etiology of diarrhea & & \\
Knew & 241 & 71.8 \\
Don't know & 96 & 28.2 \\
Total & 337 & 100 \\
Knowledge about VAC (Vitamin-A capsule) & \\
Knew & 219 & 65 \\
Don't know & 118 & 35 \\
Total & 337 & 100 \\
\hline
\end{tabular}

The study showed that among the mothers, around $68 \%$ women did not have any idea about balanced diet. Only 36.2\% women knew about protective food. Thirty eight, seventy two and sixty five were the percentage of knowledge about etiology of night blindness, diarrhea and VAC (vitamin-A capsule), respectively (Table 12).

Table 13. Distribution of mother's by their knowledge about the food sources to prevent diet related disease.

\begin{tabular}{lcl}
\hline Parameters & Frequency & Percentage \\
\hline Food sources to prevent Night Blindness & \\
Correctly knows & 126 & 37.4 \\
Don't know & 211 & 62.6 \\
Total & 337 & 100 \\
Food sources to prevent Anemia & \\
Correctly knows & 33 & 9.8 \\
Don't know & 304 & 90.2 \\
Total & 337 & 100 \\
Food sources to prevent Goiter & \\
Correctly knows & 110 & 32.6 \\
Don't know & 227 & 67.4 \\
Total & 337 & 100 \\
\hline
\end{tabular}

The study revealed that around $62 \%$ women did not correctly know about food sources to prevent night blindness. Only $9.8 \%$ mothers knew about food sources to prevent anemia and $67.4 \%$ did not know about the food sources to prevent goiter (Table 13).

Table 14. Distribution of mother's by postnatal care.

\begin{tabular}{lll}
\hline Parameters & Frequency & Percentage \\
\hline \multicolumn{2}{l}{ Mother's desire for continuing exclusive breast feeding } & \\
Less than 6 months & 37 & 11 \\
Six months & 125 & 37 \\
Greater than 6 months & 91 & 27 \\
Two years & 39 & 11.7 \\
Until the child reject & 25 & 7.4 \\
Others & 20 & 6 \\
Total & 337 & 100 \\
Mother's desire of continuing breast feeding & \\
Less than two years & 225 & 66.8 \\
Two years & 14 & 4.2 \\
\hline
\end{tabular}




\begin{tabular}{lll}
\hline Parameters & Frequency & Percentage \\
\hline More than two years & 98 & 29 \\
Total & 337 & 100 \\
Reasons of rejection breast feeding & \\
Child don't get breast milk & 60 & 17.8 \\
Don't want to eat & 6 & 1.8 \\
Mother don't like to feed & 3 & 0.9 \\
Due to the figure concern & 3 & 0.9 \\
Others & 8 & 2.4 \\
Not applicable & 257 & 76.2 \\
Total & 337 & 100 \\
Procedure of initiation of complimentary feeding & \\
Gradually & 244 & 74.8 \\
Abruptly & 93 & 25.2 \\
Total & 337 & 100 \\
Types of complimentary food & & \\
Home made & 279 & 82.8 \\
Canned food & 14 & 4.2 \\
Others & 44 & 13 \\
Total & 337 & 100 \\
\hline
\end{tabular}

Study showed that $37 \%$ mothers exclusively breast feed their children for six months. Around $67 \%$ mother desired to continue breast feed their baby for less than 2 years. Around $19 \%$ rejected breast milk earlier due to less availability of milk. About $75 \%$ initiated complimentary feeding gradually and approximately $83 \%$ used homemade food as complimentary food (Table 14).

\section{Conclusion}

The findings of the study are a matter of concern. The study populations is not only poverty stricken, but also their knowledge is poor. Most of them have less than adequate knowledge on health, hygiene, reproductive health, antenatal care, post natal care, nutrition and nutritious food to lead a healthy and active life. Food taboos during pregnancy and lactation in the study area can cause serious damage to the health of mother and child. Their traditional beliefs against colostrum feeding deny new born infants essential nutrients and protection against disease. Newborn survival is inextricably linked to the health of the mother. About $80 \%$ of all married women got married before the age 18 . There are $21 \%$ women below the normal level of BMI. There is virtually absence of any education on reproductive health and consequence of childhood marriage. The antenatal and postnatal care services availability is not yet satisfactory. Many women are yet now not able to take antenatal visit due to lack of scope and poor transport facilities, and even some women don't feel the necessity of antenatal care. Even now there is not available health service in every locality and in some areas, the provisions of this service providers failed to attain the satisfaction. About $90 \%$ of delivery is done by TBA. Among $16 \%$ women suffer from pain in lower abdomen, about $15 \%$ women suffer by edema, about $15 \%$ women suffer from 
vomiting and 44\% women have no problem. Only $24 \%$ women are concern about extra food during pregnancy. $17.2 \%$ Women are not in the complete coverage of TT vaccine. Only $66.5 \%$ women are taking more than 150 iron tablets during their pregnancy period. About $19 \%$ women are taking folic acid tablets. About $65 \%$ women are known about VAC. Only 38\% know about the causes of Night blindness.

Besides these, we can see that their family food security was not enough. From food frequency table, we saw that their animal protein and fat consumption was very low. Moreover, intra-family misdistribution is found. In most poor socio-economic society, the family heads obtain the major portion of food and then remaining of the food is distributed to children and other older family members and then the rest for mothers. But mothers should get the first priority. So, they get malnourished and gives birth LBW (low birth-weight baby) baby. These LBW baby are more prone to obesity in their future life.

In order to simplify analysis at this level, the underlying causes may be grouped into three main clusters: basic health services and a health environment, household food security and knowledge about nutrition. Household food security (adequate access by the household to amounts of food of the right quality to satisfy the dietary needs of all its members throughout the year) requires special attention where we found that mothers were at high risk of food insecurity.

Inadequate or improper knowledge of mothers regarding nutrition and health was another reason behind the poor birth outcome. The poor level of knowledge leads to wrong attitude and practices as well.

In pregnancy, the kind of family treatment was available for the mothers, their food pattern, resting schedule, immunization, iron tablet consumption, health services, and pre-natal checkups were insufficient. These entire things did affect the safety of pregnancy and survival of the newborn.

\section{References}

1. I. Saba, Traditional Beliefs and Practices that Affect the Health of Women and Children in Eritrea, Asmara, September, (UNFPA/ UNICEF, 1996) pp. 16 (access on July, 2014).

2. M. C. Latham, Human Nutrition in the Developing World (Food Agriculture Organization of the United Nations, Rome, 1997) 1, 5 pp. 45.

3. P. Papathakis and N. Rollins, WHO, 2, pp. 6, (2005) (access on July, 2014).

4. E. Sines, U. Syed, S. Wall, and H. Worley, Policy Perspective on Newborn Health (2007). (access on July, 2014).

5. K. M. A. K. Azad, J. Sci. Res. 1(1), 72 (2009). http://dx.doi.org/10.3329/jsr.v1i1.1055

6. T. Sabita, The Determinants of Newborn Care Practices in the Rural Areas of Nepal (University of Canterbury, 2010). http://ir.canterbury.ac.nz/bitstream/10092/5061/3/Thesis fulltext.pdf. (access on July, 2014).

7. M. N. Hasan, M. Z. Sultan and M. Mar-E-Um, J. Sci. Res., 6(2), 373 (2014). http://dx.doi.org/10.3329/jsr.v6i2.16530

8. UNICEF, Causes of Malnutrition (Oxford University Press, 1998) pp. 24. http://www.unicef.org/sowc/archive/ENGLISH/The $\% 20$ State $\% 20$ of $\% 20$ the $\% 20$ World $\% 27 \mathrm{~s}$ \%20Children\%201998.pdf. (access on July, 2014). 
9. M. Berer and T. K. S. Ravindran, Reproductive Health Matters (Blackwell Science Ltd., 2000) pp. 1.

10. The World Bank, Safe Motherhood and Maternal-Health (2014).

http://web.worldbank.org/WBSITE/EXTERNAL/TOPICS/EXTHEALTHNUTRITIONAN DPOPULATION/EXTPRH/0, contentMDK:20200213 menuPK:548457 pagePK:148956 piPK:216618 theSitePK:376855,00.html. (access on July, 2014).

11. Krishna, J. Obs. Gyn. 1, 15 (2000).

12. C. Cullion, Int. J. Obs. Gyn. 7, 311 (2002).

13. F. Ferdous, Study Mode, p. 1 (2013). (access on July, 2014).

14. S. B. Lisa, Nutrition Requirements During Pregnancy (Jones and Bartlett Publishers, 2014) 1, pp. 1. (access on July, 2014).

15. M. N. Hasan, M. Akhtaruzzaman, and M. Z. Sultan, J. Anal. Sci, Meth. Ins. 3, 24 (2013). http://dx.doi.org/10.4236/jasmi.2013.33A004

16. UN, Millennium Development Goals and Beyond 2015 (2014).

http://www.un.org/millenniumgoals/pdf/Goal 5 fs.pdf. (access on July, 2014).

17. Bangladesh Economic Review, Ministry of Finance, Bangladesh. 1, p. 10 (2014). http://www.mof.gov.bd/en/budget/14_15/ber/bn/Index_\&_Indicators_bn_2014.pdf. (access on July, 2014).

18. M. N. Hasan and M. N. I. Khan, B. S. Project on 'The Pregnant and Lactating Mother's KAP (Knowledge, Attitude and Practice) and Nutritional Care during Antenatal and Postnatal Period in Ukhia, Cox's Bazar, Bangladesh' (Institute of Nutrition and Food Science, University of Dhaka, Bangladesh, 2010). 